\title{
20. Playing with power: Casual politicking as a new frame for political analysis
}

\author{
Alex Gekker
}

\begin{abstract}
The chapter examines the entanglement of play and politics through digital media. By analyzing the Obama 2008 and Trump 2016 presidential campaigns, it proposes a new term for examining political engagement, namely 'casual politicking.' Building on mediatization theories, the chapter takes the affordances of causal video games as a template to analyze the actions performed by citizens, politicians, and organizations attempting to alter behaviors. The resulting characteristics of the political process are presented through four key aspects: the role of ICT platforms with intuitive interfaces, the prevalence of issue-centered rather than ideological action, a perpetual political engagement undeterred by failure, and socially focused networks orientated towards fun. When applied to the two campaigns, surprising similarities can be seen, despite the different messages and personalities of the candidates.
\end{abstract}

Keywords: Casual politicking, casual games, mediatization, elections, Obama, Trump

This chapter deals with the tricky duality of politics and play for the contemporary citizen. Arguably, politics is and always has been playful. In his famous treatise on playfulness, Johan Huizinga sees the playful (agonistic) origins of law in the courts of the Greek and Roman lawyer-politicians. In a later chapter, he analyzes the playfulness of war and peace in medieval society and mourns the loss of such playfulness in contemporary times (Huizinga 1970). Brian Sutton-Smith (2005) calls this type of interaction 'play as power,' hailing from ancient sporting events and contests. Similarly, mediatization scholar Stephen Coleman $(2006,2011)$ tracks the changes

Glas, R., S. Lammes, M. de Lange, J. Raessens, and I. de Vries, eds. 2019. The Playful Citizen. Civic Engagement in a Mediatized Culture. Amsterdam: Amsterdam University Press. DOI: $10.5117 / 9789462984523 / \mathrm{CH} 20$ 
in the voting and participation habits of young people with the advent of televised voting for Big Brother-style reality shows. However-as I will argue below-political play has changed considerably since it merged with the digital affordances of new media platforms, resulting in autotelic political play that is centered on issues and platforms rather than concrete ideologies. To illustrate this, I highlight two turning points in world politics: the campaign that led to the election of Barack Obama as President of the United States in 2008, and the campaign that elected his successor, Donald Trump. Provocatively, I claim that these campaigns were identical in their underlying principles, despite the differences in the ideology and personality of their respective candidates.

In doing so, I aim to offer a view of playful political processes through the contemporary lens of digital media by bridging the gap between two disciplines that have rarely met, namely game and play studies on the one hand and political communication on the other. In an introductory chapter to the influential anthology Political communication in postmodern democracy: Challenging the primacy of politics, the editors warn that "as readers, listeners and viewers learn to recognize the manufactured nature of news, cynicism and disillusionment with politics grows and with it a dramatic erosion of trust and political engagement" (Brants and Voltmer 2011a, 6). The word 'users' is absent from this warning, yet users are perhaps the most common conceptualization of the masses to date and, in fact, as pointed out by visualization guru Edward Tufte, "[t]here are only two industries that call their customers 'users': illegal drugs and software” (Whitlatch 2015 , n.p.). Unlike in narcotics industries, however, political-socio-technical processes are in a constant state of flux and renegotiation between various parties, users and producers alike. 'Usage' does not imply unidirectionality, as research has shown that in complex technological processes designers and users 'co-configure' each other continuously (Woolgar 199o; Bruns 2007). Therefore, I argue that to understand the remaking of what it means to be engaged in contemporary mediated politics, we must look at users and even more so at players.

This chapter is divided into two sections. The first section introduces my main theoretical framework. Utilizing the hybrid human/nonhuman perspective of the Actor-Network Theory (ANT), I conceive mediatized political engagement as shaped through playful performative practices and enabled by casual devices. Unlike the sporting metaphors or grand battles associated with political play, I suggest that casual games should be used as our primary analogy. The second section outlines my concept of casual politicking, and its properties of reliance on ICT platforms, issue networks, 
perpetual engagement, and social media sites. Throughout this chapter, I will discuss the 2008 Obama app and Trump's 'Great Meme War' in 2016 as two poignant historical case studies exemplifying casual politicking mechanisms. Ultimately, I offer a view of the ludification of politics in which action is contingent on the perceived enjoyment of - and affordance to-users.

\section{Games as mediatization of politics}

This section will show that a type of video game referred to as 'casual games' can be used as a productive prism for understanding certain types of political engagement. In the first subsection, I briefly problematize classic theories of political communication in relation to current modes of media consumption, and suggest mediatization theory as a solution. Mediatization presupposes the existence of certain 'molding forces' whereby media technologies and institutions mold previously non-mediated spheres of life. In the second subsection, I argue that casual games are a type of medium that can and should be examined in relation to political mediatization.

\section{Mediatization}

Video games are an example of networked media, becoming widespread through the convergence of platforms and technologies (Jenkins 2006a; Jenkins 2006b; Moore 2011; Sicart 2014; Walz and Deterding 2015). The field of game studies that has emerged around them is multifaceted and conflicted, hailing from computer science, cultural studies, play studies, and Human-Computer-Interface (HCI) studies. In this chapter, video games are postulated as an established communication medium, rendering it possible to examine the potential of games and game studies as a prism for political research. This follows the notion of political agents as tactical producers and consumers of media, as has been conceptualized in recent scholarship (Fuchs et al. 2014; Tufekci 2017).

Agenda setting and framing are two fundamental theories for political communication in general, and for my notion of casual politicking in particular. Ever since McCombs and Shaw (1972) published their ground-breaking research on what they dubbed the agenda-setting effect, researchers have studied the media's ability to set agendas for the public and political establishment by putting certain topics in the spotlight while downplaying others. Or, as McCombs and Shaw quote Cohen in the opening pages of their work: 
"[T]he press may not be successful much of the time in telling people what to think, but it is stunningly successful in telling its readers what to think about" (Cohen 1963, 13, emphasis in original). While the findings regarding the agenda-setting effect vary in terms of the strength, directedness, and homogeneity of effects, it is generally agreed that media are responsible for highlighting a set of topics that influence public opinion (Scheufele and Tewksbury 2007). Increased public concern subsequently influences the attention given to those issues by public officials, who consequently try to attract the media's attention with topics fitting their own interests, and so on, ad infinitum.

The second theory, framing, was developed through the application of psychologist Erving Goffman's (1974) frame analysis theory. Goffman suggests that our daily experience is organized through a series of 'frames,' or referential models with which we approach each situation. We use different 'keys' to refer to different frames, depending on our heuristics and predispositions. Such frames might include, for example, 'play' or 'rehearsal' as opposed to 'serious situation.' In other words, a person is able to make a distinction between their understanding of an argument in the frame of a theater play and an argument in the frame of observing an incident in the street. Framing as media theory (Entman 1991, 1993; Iyengar 1994) builds upon this and suggests that the media repackages certain aspects of stories for their audiences in a way that influences the broader context within which the stories are understood. These aspects may include words, photographs, or interviews emphasizing certain things, but also elements such as the color chosen for the graphics or the visual arrangement of material on the page or the screen. Word choices, the placement of photographs, or even the colors used on a page or during the newscast invoke certain referential frames for an audience. One famous example of frame analysis was conducted by communication researcher Robert Entman (1991), who examined two similar aerial tragedies, the shooting down of a Korean civilian airplane by the Soviets and the shooting down of an Iranian civilian airplane by United States troops. He shows how the American press framed one case as a tragic mistake (using words such as "tragedy" and "plane passengers") and the other as a deliberate crime ("attack," "victims," and portraying the plane in crosshairs).

Agenda-setting and framing theories are considered the cornerstones of modern political communications, yet they represent a research paradigm no longer sufficient for understanding modern mediated communication. As economic and technological networks converge to offer a personalized (political) experience (Jenkins 2006b; Couldry and Hepp 2016; Chadwick 
2017), the networked society supplements mass communication with mass self-communication (Castells 2007). Such structures are dominated by a flat network of internet peer-to-peer communication, rooted in social media sites, email, online games, and micro-blogging rather than by the hierarchies of traditional media - though still reliant on them for broader appeal. While traditional media institutions still set the agenda and frame it, everyday users today have much greater ability to do the same, by 'poaching' and 'repackaging' meanings provided by mainstream sources (Jenkins 2006a, 2012; Schäfer 2011). This greatly undermines the power of such traditional media institutions to set and frame agendas, as can be seen through the massive bottom-up activist campaigns of \#BLM and \#MeToo that originated on Twitter. Facebook, for example, has emerged as a dominating force on the web, inducing a significant change in how information is exchanged and evaluated (Gerlitz and Helmond 2013; Helmond 2015). And while scholars and activists have long warned about the ramifications of an algorithmically curated public sphere, it took several years and Facebook's own admission of unwilling compliance with Russian interference in United States elections to cement awareness of this change in the public's mind.

There seems to be an increased enveloping of different social spheres within mediated communications. This, in turn, affects how those spheres behave and what sort of discourse arises, a process that is referred to as mediatization. While 'convergence,' a concept used to describe the media changes mentioned above, brings to mind a technical term and a process of one-sided integration, 'mediatization' on the contrary implies elasticity and reciprocity: the web affects political discourse as much as corporate mergers affect televised content distribution methods. In it, we find traces of globalization anthropologist Arjun Appadurai's (1996, 2001, 2013) views of the world's composition as constantly shifting and changing scapes (ethnoscapes, technoscapes, financescapes, mediascapes, and ideascapes), multiple geographies that are leaking through each other - thus creating a global blur of cultures and images. Building on the notion of imagined communities (Anderson 1983), Appadurai raises the importance of imaginary spaces as global social practices that tend to weaken the nation states and lead to the creation of deterritorialized communities of immigrants and 'wannabe nations.' Such modern practices, I argue in response, have an inherent resistance to the classic agenda-setting and framing effects of the media because they are dispersed, multi-modal, and constantly reconfiguring.

Prominent communication researchers Bennett and Iyengar (2008) suggest that the changes in audience fragmentation, media authority, and news consumption are leading to a change in the way audiences form opinions 
and interact with political processes. According to them, communication research continues to be "adrift theoretically, seldom looking back to see where foundational modern theory needs to be adapted and, in some cases, overthrown, in order to keep pace with the orientations of late modern audiences, and new modes of content production and information delivery" (Bennett and Iyengar 2008, 713). They argue for a return of a 'minimal effects' era in research, concentrated on the diminishing power of institutions to dictate agendas, alongside the growing significance of choice in media consumption and the ability to surround yourself with reinforcing political attitudes in an 'echo-chamber' or distance yourself from political discourse and conduct altogether. They lament the fixation on "findings-driven controversies in political communication" (Ibid., 709) and instead propose focusing on developing a theoretical framework "that may reconcile the paradox between the growing centrality of media in governance processes and its shrinking credibility and attention focus in the lives of citizens, particularly given the waning of mass media influence in the lives of most citizens" (Ibid., 714). This highlights the problem of traditional communication research, with its imposition of unidirectional effects-driven findings, when applied to modern modes of political mediation.

Such entanglements of political and media institutions have come to be known as part of the research direction referred to as mediatization research. According to sociologist and mathematician Friedrich Krotz (2007), mediatization is a metaprocess that occurs in parallel to and with other metaprocesses (globalization, migration) and informs knowledge construction, identities, social relations, and organizational structures. It takes into account longitudinal shifts in communicative processes mediated by various forms of technological mass media and new media. While diverse and not free from internal debates, the mediatization perspective recognizes that there is an ongoing entanglement of media infrastructures and institutions with other, previously separate social spheres. The resulting change is that certain fields that could previously be separated into their own analytical domains, for example politics, religion, or family life, are becoming increasingly modified by the way they are mediated (Hjarvard 2008, 2013; Lundby 2009; Brants and Voltmer 2011b; Hepp 2012, 2013; Couldry and Hepp 2016). Some have argued that this perspective faces the peril of descending into the pitfall of media-centric technological determinism, particularly focused on new technologies (Deacon and Stanyer 2014). The proponents of the approach retort that, while disagreeing on the extent of mediatization in terms of historic continuity and the role of certain platforms, the goal is to focus scholarly attention on distinguishing 
[b]etween being 'media-centric' and 'media-centered.' Being 'mediacentric' is a one-sided approach to understanding the interplay between media, communications, culture, and society, whereas being 'mediacentered' involves a holistic understanding of the various intersecting social forces at work at the same time as we allow ourselves to have a particular perspective and emphasis on the role of the media in these processes. (Hepp, Hjarvard, and Lundby 2015, 316)

Andreas Hepp clarifies in an earlier work that mediatization is not "a question of a 'causal effect' of a certain media (technology). Media as such only become concrete in communicative action; however, they offer a certain 'potentiality of action' in such a figuration, which can be called the 'molding forces' of the media, and have to be analyzed in a contextualized way" (2012, 17). He utilizes concepts from Actor-Network Theory (ANT) (Latour 1987; Latour 2005b; Law 1992) to strengthen this theoretical framework, since its scope aims for the exploration of social processes involving the conjunction of humans and technology. ANT argues that in order to understand modern society, a researcher must follow the 'work-nets' of human and non-human actors — or rather, actants (Latour 2005b) —in producing cultural-material artefacts, referred to as chains of associations. We can thus facilitate meanings by tracing and relating the different actors to one another, wherein agency is distributed among them. Such a theory of mediatization presents technological endeavors as "coagulated actions" (Hepp 2012,16) of human and non-human actants. Hepp argues that mediatization should be viewed as a metaprocess where media are not transparent instances of communications but institutionalized sociocultural processes, consisting of the coagulated actions of press institutions, governmental actors, the technologies that allow them, and relevant idiosyncratic uses of them in each case by the users (viewers, participants). This conceptualization of mediatization is built not on a specific media logic, or even logics, but on "the moulding force of the media" (Ibid., 17). This mediatization framework infused with ANT is what allows me to contextually analyze the respective campaigns of Obama and Trump in the section below on casual politicking. It presupposes that socio-technical changes in modes of communication are fueled by a combination of (1) developing technological practices and (2) the institutional changes of political and media organizations in response to these practices. Moreover, it draws attention to the necessary shift in what it means to 'do politics' when examined through the prism of such shifts. 


\section{Games}

Here, we return to the appropriation of games and the field of game studies for cultural enquiry. By tracing specific manifestations of the mediatization metaprocess, I show how the molding forces of digital play congregate and operate within political spheres. One can no longer talk of unidirectional effects on the public, as in the case of agenda setting and framing, but on how the media penetrates, infuses, and resonates along with various other social practices. Thus, as mediatization implies, the continued growing entanglement of additional spheres of life with specific media logics leads to the hybridization of communicative and cultural practices. I follow Joost Raessens's $(2006,2014)$ suggestion that games and other digital technologies facilitate playful goals and identities, leading to the "ludification of culture." This idea was summarized by the prominent game developer and theoretician Eric Zimmerman in an interview for Jesper Juul's book on casual games (2010). In the interview, Zimmerman notes:

[a]s digital technologies and networks of information, the Internet, computers, mobile technologies, more and more pervade our lives, [and] the ways in which we socialize and flirt and communicate and learn and work and do our taxes and engage with our government and manage our finances, and many, many other important aspects of our lives, the more I think our culture becomes primed for play and particularly, games as the dominant form of leisure. Because games are the form of culture that is most intrinsically related to those things, to systems, technology, information, and mediated communication, [...] play becomes a more dominant paradigm for culture rather than the moving image. (Juul 2010, 215)

Here Zimmerman evokes the idea of playfulness as a major component of various human activities, underlying modes of being beyond leisure, later reinforced in his Manifesto for a ludic century (Zimmerman 2015). Moreover, he draws a conceptual link between the abstract idea of play and the notion of play as embedded in computerized systems, making computation itself playful, in what Sebastian Deterding defines as the 'rhetoric of systems' (Deterding 2015), which is explored further below. It is built on the argument of play as a prerequisite for culture, drawing from Homo ludens (published originally in 1938) in which the Dutch historian and anthropologist Johan Huizinga (1970) suggested the then-revolutionary notion that play is present in most areas of human activity. It is the basis for law, politics, religion, commerce, war, and most other human endeavors. To 
support this argument, he pointed to the 'play-element' of ancient Greek and Indian mythology, riddle-games in ancient civilizations, medieval tournaments, and carnivals, as well as the beatification process of Christian saints. The French sociologist, critic, and philosopher Roger Caillois (1958/2001) later criticized and refined Huizinga's overtly broad definition of play. Caillois made a distinction between ludic activities centered on competition, such as sports or gambling, and activities of free play, such as theater, music, or carnivals. He introduced the idea of play as a voluntary activity and tied the act of playing to make-believe-which was lacking in Huizinga's original definition.

Following on from these two pioneers, the debate on the role of play in various human activities has been extended to include biologists, sociologists, psychologists, historians, mathematicians, and designers. In particular, play has been examined by game designers, a profession emerging with the growth of leisure time in post-industrial societies and the culture built around tabletop games and later on computer games. Designers took a specific, practical interest in the notion of play, trying to understand how play is present in games and what sorts of rules and guidelines games should follow in order for them to be an enjoyable, playful activity. As digital (and to some extent, tabletop) games have become distinct cultural artefacts, academics have started to pay interest as well. In 2003, the Digital Games Research Association (DiGRA) was established and its first conference was held, further demarcating games from play. The field of game studies (Aarseth 2001; Raessens 2016) builds on play research by combining classic notions of play with modern insights taken from the fields of HCI and interactive design as well as cultural analysis rooted in film and television studies.

Katie Salen and Eric Zimmerman (2004) note that as digital technologies, computers, and video games develop, a familiar definition is sneaking into the field: that of games as systems coined by writer and game designer Chris Crawford (1982). Building on Crawford, Salen and Zimmerman suggest that a game is "a system in which players engage in an artificial conflict, defined by rules, that results in a quantifiable outcome" $(2004,80)$. Another elaboration of Crawford's definition was proposed by Juul (2003, 35): "A game is a rule-based formal system with a variable and quantifiable outcome, where different outcomes are assigned different values, the player exerts effort in order to influence the outcome, the player feels attached to the outcome, and the consequences of the activity are optional and negotiable."

What I find interesting about these supplemental definitions is that they could just as easily apply to modern political processes, especially when 
these processes take place in a mediatized environment. The fact that so much of our contemporary political jargon rests on metaphors of a contest, a race or a game is not a trivial thing, since metaphors-as Lakoff and Johnson $(1980,1999)$ remind us - are more than just words; they represent our experience in the world, which is shaped and framed by the signs we use. Elections are a simple example. The players and the rules are there, while the results are certainly quantifiable: e.g. election win percentages and the number of seats in parliament. Regarding the artificiality of the conflict, this is mostly a question of worldview. However, even as we turn away from this very obvious example (after all, election campaigns have long become synonymous with 'games' or 'races'), the elusive association remains. The 'system' in the definition contributes a great deal to this. 'System' (together with 'network' or 'algorithm') is the organizational metaphor of the network society (Castells 2001, 2007; Galloway 2004; Van Dijk 2005). This idea lies in the specific understanding of play as systematic (Deterding 2015) and it reminds us of computers, communication infrastructures, logical patterns, and mathematical topographies-all those things that were not necessarily associated with politics but now are. Perpetual campaigns, media monitoring, polling, and calculated political advertising are all part of news management strategies undertaken by contemporary establishments (Brown 2011), as fully revealed in the Cambridge Analytica scandal and its reliance on psychometric data collected from Facebook users for political campaigning (Graham-Harrison and Cadwalladr 2018). Journalistic practices are becoming similarly systematic, quantifiable, and algorithmized via web metrics, ratings, subscription figures, and opinion polls (Christin 2018). As noted above, digital games do seem to be the cultural form most closely associated with our digitalized-networked age by modern play theorists. To understand the role of the digital game within mediatized society, let us trace its characteristics.

Unlike other media, the technological affordance of games allows multiple participants to engage with content repeatedly under similar conditions, individually or through collaborative effort. In this context, a single playthrough has diminished significance compared with the broader game capital and meta-game practices such as socializing or asking other players for help (Steinkuehler 2004; Consalvo 2007; Shaw 2010; Corliss 2011). As Simon, Boudreau, and Silverman (2009) have shown with their exploration of players of the game Everquest (Sony Online Entertainment 1999), performance is never calculated simply as a momentary score of kill points, but is instead a confluence of game mechanics, personal track record in relation to others, online social experience, and offline understanding of the play context, 
over a period of time. This accumulation of social capital via engagement with playful systems is what draws me to examine video games through the prism of mediatization theory. I claim that as the political becomes increasingly mediatized, games become an expanding, different type of media, reaffirming within themselves characteristics associated with the network society as a whole. The continuous ludification of culture (Raessens 2006, 2014; Jahn-Sudmann and Stockmann 2008; Pargman and Jakobsson 2008; Roig et al. 2009; McGonigal 2011; Fuchs et al. 2014; Walz and Deterding 2015) is exhibited in the trickling spread of digital games beyond the boundaries of the home and arcade parlor and into broader cultural forms. From a separated, dedicated activity associated with a certain gender and class (Cassell and Jenkins 2000; Flanagan 2009), games have grown into a mainstream media consumption practice, to the point that "games have become so successful in 'colonizing' the sphere of everyday activities that playing them becomes transformed into a mundane act, comparable to watching television (to kill time) or cooking (to fill one's belly)" (Pargman and Jakobsson 2008, 234). ${ }^{1}$

In parallel, games and game elements are frequently being incorporated as design methodologies in computerized fields as distinct as advertising, education, and corporate training, resulting in the paradigm of 'gamification' - the inclusion of game elements in non-game systems (Deterding, Dixon et al. 2011; Deterding, Sicart et al. 2011; Fuchs 2012; Fuchs et al. 2014). This aspect of games as a widespread cultural phenomenon is thoroughly explored by Jesper Juul's (2010) foray into the phenomenon of 'casual games,' the immediate precursor to the adoption of gamification. He combines ethnographic studies of players, interviews with developers, and comparative analyses of the game industry, and stresses that the abundance of such games has made the format accessible and accepted over multiple platforms and devices. Today, Juul notes, "[t]o play video games has become the norm; to not play video games has become the exception" (Juul 2010, 8). Digital games, from the workplace time-killers Solitaire and Minesweeper to smartphone staples like Angry Birds (Rovio 2009) and Candy Crush Saga (King 2012) to the top-selling ('Triple-A') blockbuster Grand Theft Auto and Call of Duty series, can thus be seen across various audiences, across age groups, gender, and income brackets. They are at the forefront of the new digital economy's

1 Arguably, Pargman and Jakobsson refer to ethnographic studies of hardcore gamers here, but as discussed next, those definitions are becoming blurred: 'casual' players occasionally spend growing amounts of time on games, while 'hardcore' players switch to 'casual' games due to lack of time. 
business model, extracting value from the experience of media in new (and often troubling) ways, from micro-transactions to behavioral tracking (Philips 2016).

The casual game is an important paradigm shift in video gaming culture, which highlights producers' attempts to address wider audiences on the one hand and audiences' growing familiarity with digital game interfaces on the other. Juul notes that from a market perspective, the modern 'hardcore' game industry (which is aimed at dedicated players who can devote time and effort to complex game learning curves) has reached saturation. Still, the inclusion of simple digital games in a variety of products (from watches to movie players) has made basic games into a common pastime of millions. Since many hardcore games are difficult to get into for casual players while casual games seem to be accessible to all, several game developers have attempted to 'casual-ize' some of the features of games, leading to simplified controls for hardcore games or the inclusion of mini-games as part of the main game. Intuitive controls on consoles like the Nintendo Wii/3DS and AR/VR applications with three-dimensional body tracking, music games from the Guitar Hero or Rock Band series, the rise of intuitive touch screen controls and the overall dominance of smartphones as personal media devices, as well as the waxing and waning popularity of Facebook and the social games played through it, are all developments that have made digital gaming more accessible and acceptable for most people.

To conclude this section, I view the proliferation of digital games as an indication of the ludic attributes of our culture, previously identified in play studies. As (casual) games become the lingua franca of the digitally engaged, certain modes of behavior associated with playing games are becoming dominant. Mediatization theory suggests that politics is affected by the molding forces of the media, and while the theory initially pinpointed television as the medium 'to blame,' later replacing it with the web and associated ICTs, I suggest that games, and especially casual games, are the direction in which mediatization theorists should be looking now. Game studies and political communication have rarely been combined until now, and I hope to provide additional food for thought by creating a new conceptual framework for studying topics of engagement, participation, and information transmission that traces the different forms of ludic political communication. I suggest this form is present in both top-bottom and bottom-up relations between the public, media, and governing officials, and I call it 'casual politicking'. 


\section{Casual politicking}

According to Juul (2010), the term 'casual game' developed over the last two decades to denote a type of entertainment software aimed at popular audiences rather than video game hobbyists. The genealogy of the casual game can be drawn from parlor card games such as Solitaire and family board games like Monopoly, alongside such early staples of video gaming as Myst (Cyan 1993), which was more concerned with the aesthetic experience than with complex game mechanics. The term is often contrasted to that of 'hardcore' games and their players, who are interested in developing complex gaming skills and willing to commit to a major time investment. However, Juul points out that the introduction of new distribution platforms has created a new economy of play time, one where simple games can be played repeatedly in short bursts, but taking up many hours over the day. Instead of focusing on time investment, Juul provides a breakdown of the design elements most strongly associated with casual games.

This section is dedicated to a two-stage argument about the applicability of Juul's design elements to the study of contemporary politics. In the previous section, I argued that digital games are an expression of the ludification of culture in digital media. Moreover, I showed that mediatization theory suggests how certain 'molding forces' in the media shape entangled social spheres, and I presented casual games as a possible venue for such an analysis. Here, I wish to operationalize this analytical framework by first synthesizing the characteristics of casual games according to Juul, and then providing certain parallels with processes of political communication. I compare the Obama 2008 election app to Trump's 'Great Meme War' strategy as a comparative case study to be analyzed within this framework. Here it must be stressed again that I do not claim any unidirectional or bidirectional effects between casual games and the political shifts I describe. Rather, the two reflect a similar trend in the information consumption and distribution practices of ICT-reliant audiences in the developed world. To begin with, I briefly introduce the two case studies and their significance before extrapolating the principles of casual politicking by synthesizing Juul's characteristics into four distinct categories.

The official Barack Obama 2008 mobile application for the iOS and Android mobile operating systems is an example of casual politicking true to its time (Ritchey 2008). Mobile communications, text messages, and applications were instrumental in the success of Barack Obama's 2008 campaign (Kiyohara 2009; Pick 2010) and the app was a major part of this 


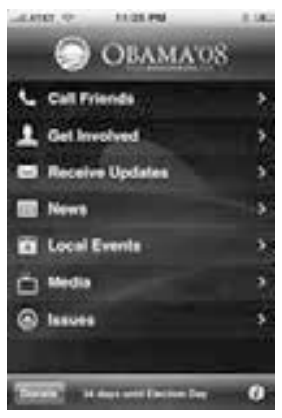

20.1: Obama '08 app home screen.

effort. The app was released after a collaborative effort by ten volunteer coders, who had decided to donate their time and skills in order to support their presidential candidate (Sagolla 2008; Pick 2010). The developers acknowledged the innovativeness of their own emergent method of contributing to the campaign and stated that the same emergent principles helped build the features they implemented in the app, saying that " $\mathrm{t}] \mathrm{he}$ app was designed as a means to donate your time in discreet segments-we call it 'micro-volunteering'” (Sagolla 2008). The application includes seven main functions (see Figure 20.1) and a "Donate" button, which played an important part in Obama's unique campaign funding method of obtaining a multitude of small donations.

Ironically, the very same principles that went into the design of the Obama app and its surrounding campaign can be identified in the making of Donald Trump's 'Great Meme War' (Nagle 2017; Lovink and Tuters 2018) — the word 'meme' here refers to the practice of creating and spreading (visual) content online (Shifman 2014), while the word 'war' evokes the character and tone of Trump's presidential campaign. This semi-facetious term, which references bloody conflicts of old yet is filled with purposefully self-deprecating humor, was favored by online supporters of Trump, claiming to have "actually elected a meme as a president" (Ohlheiser 2016, n.p.) While Trump's campaign also featured the option to donate money in a similar fashion to the Obama app, the main conceptual innovation of Trump's campaign was utilizing micro-volunteering for cultural meaning-making (see Figure 20.2), and cross-pollinating various political right-wing groups (loosely identified as the 'Alt-Right') by Trump's chief strategist Steve Bannon. The latter presided over the popularization of the Alt-Right identity in his previous position as the editor of Breitbart News, and maintained ties to this community throughout the campaign until his later departure from Trump's White House team (Neiwert 2017). 


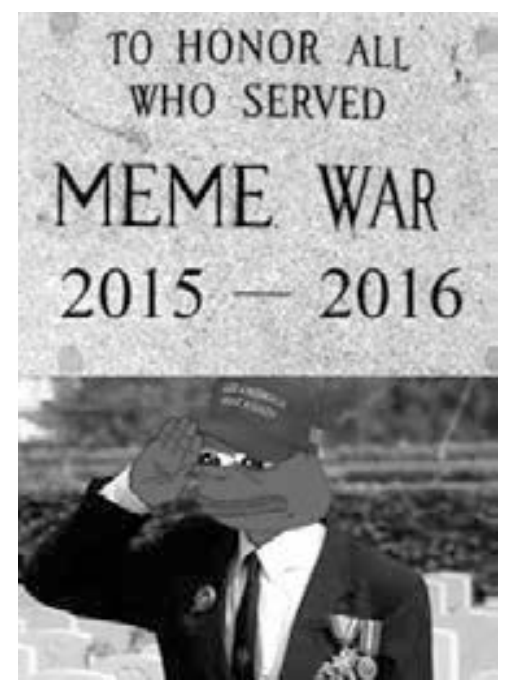

20.2: One of the images from the titular page on the 'Great Meme War' Encyclopediadramatica website, depicting Pepe the Frog (an unofficial mascot of online Trump supporters) saluting the 'fallen'.

Understanding these two pivotal moments in political participation requires us to take a brief detour to the world of casual games, and their unique properties for capturing and holding the user's attention (see Table 1, left column). First and foremost is the concept of 'juiciness', relating to these games' design patterns. Juiciness is embodied in the visceral interfaces that prioritize immediate visual and aural gratification, intuitive control, simplification of tasks, and a clear definition of goals. Usability is a major component in juicy design. ${ }^{2}$ Games in general have outstanding interaction design methodologies, communicating their objectives via tutorials and gameplay rather than through external training. Unlike other kinds of software, casual games are developed for quick and easy play, aimed at a non-technical audience, in a context where complex instructions are impractical. A juicy interface values simple controls with immediate feedback, often in non-diegetic form as in text that appears on the screen congratulating players on successful actions. A second characteristic is interruptibility, which means designing the game in such a manner that a play session requires little effort. Casual games are designed to be played in short bursts. Be it a social network game that runs server-side through the

2 Although Juul separates juiciness from usability, the former is reliant on the latter, as a usable and intuitive interface will determine whether the juicy elements become apparent. For my discussion, it is sufficient to include both terms under one category. 
website interface and requires no save/load functions, or a console game that breaks play into small segments (levels, missions, mini-games), such games allow users to adjust the playing time to suit their schedule rather than vice versa. ${ }^{3}$ Thirdly, casual games exhibit a forgiving attitude toward mistakes. This is not to say the games are not hard, but they are designed in such a way as to avoid making players have to repeat large portions of game play if they make a mistake. Finally, all casual games exhibit a tendency to involve social connections as part of the game design, either by making the game multi-player or by promoting features such as leader boards and providing bonuses for inviting friends and family (Juul 2010).

Similar principles can be applied to tracing casual politicking. To date, many critics of online modes of political engagement depict them as shallow and non-consequential. Terms like 'slacktivism' or 'clicktivism' (Morozov 2014) highlight the low threshold of computer-mediated political engagement, both on the side of the political establishment and on that of ordinary citizens. To engage with the political only online, in other words, is not serious politics. Instead, I offer the term 'casual politicking' as a more nuanced alternative to the pessimistic view of contemporary political participation online. With this term, I wish to evoke-in conjunction with the aforementioned characteristics of casual games - an unplanned, emergent, and self-organizing mode of conduct, rather than a binary, rigid structure of serious versus non-serious politics. It relies on four key aspects, which we can equate with the four casual gaming operating principles discussed earlier (see Table 1, right column).

First, such modes are facilitated by ICT platforms that exhibit interface and affordance equivalents to the juiciness elements of casual game design. Second, casual politicking relies on issue-centered rather than ideologycentered conduct, which, when coupled with ICT platforms, generates an interruptible political mode for various actors. Users follow and connect with those issues that are relevant to them, contributing in each case according to their time and resources. Third, users exhibit perpetual political engagement, resonating with the low price of failure characteristic of casual games. In other words, there is a fluid and continuous engagement with issues on the side of politicians and citizens alike that allows for a quick recuperation in case of failure, while avoiding major disappointments and a sense of

3 'Casual players' can still spend long hours on games. Juul's survey indicates that fourteen per cent of casual players dedicate more than 40 hours a week to playing games. Similarly, almost one third of baby-boomer gamers in the United States spend 20 hours playing a week (Pearce 2008). The game simply allows for shorter individual play sessions. 
setbacks. Lastly, just like in casual gaming, sociability is the driving force of casual politicking. This is reflected by involving networks of like-minded people in the political process, heavily relying on the social capital aspect of actions rather than on the perceived outcome.

Table 1: Comparison between involvement principles underlying casual gaming and those underlying casual politicking

\begin{tabular}{|c|c|}
\hline Casual gaming & Casual politicking \\
\hline $\begin{array}{l}\text { Juiciness: Rich visceral interfaces for } \\
\text { immediate gratification }\end{array}$ & $\begin{array}{l}\text { Intuitive interfaces: Accessible, reliable, and } \\
\text { highly visualized interface for immediate } \\
\text { information and engagement, with a high } \\
\text { level of affordance }\end{array}$ \\
\hline $\begin{array}{l}\text { Interruptibility: Intended to be played } \\
\text { in short bursts, minimal save/load } \\
\text { compatibility }\end{array}$ & $\begin{array}{l}\text { Issue-centered: Engagement for the shorter } \\
\text { political/media attention span through } \\
\text { clictivism and meme wars }\end{array}$ \\
\hline $\begin{array}{l}\text { Forgiving attitude toward mistakes: A game } \\
\text { may be hard, but failure does not result in a } \\
\text { massive setback }\end{array}$ & $\begin{array}{l}\text { Low price of failure: Perpetual processes } \\
\text { minimize each engagement's cost and } \\
\text { reduce the entry barriers }\end{array}$ \\
\hline $\begin{array}{l}\text { Socially driven: Existing ties are important } \\
\text { parts of the play experience }\end{array}$ & $\begin{array}{l}\text { Socially driven: Existing ties and networks } \\
\text { are important parts of the participatory } \\
\text { experience, which underscores fun rather } \\
\text { than ideology }\end{array}$ \\
\hline
\end{tabular}

\section{Accessible interfaces in ICT}

ICT networks with high-affordance accessible interfaces facilitate direct and visceral experiences that require little in the way of technical or political education. More and more political content migrates to platforms where ideologies are simplified in infographics and participation is achieved by signing an e-petition or sharing a link on your social media site profile, such as the embedding of Facebook's 'Like' buttons on an external website that lets users like' a certain topic or personality and then receive communication about it in their feed (Helmond 2015).

Moreover, this ubiquitous access to information is provided by constantly simplifying and homogenizing access to digital data. This is done through a better understanding of computer-mediated usability (Nielsen and Pernice 2008) as well as through the growing distribution of mobile wireless devices, which become embedded in the urban experience, manifesting a renewed connection between the city, its inhabitants, and the information they produce/consume (Mitchell 2003; Nunes 2006; de Souza e Silva 2006; de Souza e Silva and Hjorth 2009). For the first time in history, mobile communication 
means that both the information carrier and the information itself are mobile-creating the possibility for the individual to be on the move while transmitting and receiving large quantities of data (Poster 2004). Casual politicking requires fast and simple access to data, and the ability to communicate while being on the move, often involving swarming (dispersed, self-organizing) modes of operation. Such traits are achieved through the imagined technological affordances (Gibson 1977; Norman 1988, 2002; Nagy and Neff 2015) of the interface, where agency results from the conjunction of a sentient (human) actor pursuing a goal and the perceived qualities of objects in the immediate vicinity that allow the actor to perform an action. Digital interfaces are often built with affordance design principles in mind, to hint, guide, and drive users. Contemporary interfaces thus create affordances for fast two-way communication, location-based action, viral news consumption, and the like.

The Obama app exemplifies this well. The first option on the app's main screen-Call Friends - links the app to the user's phone book, sorting their contact list according to U.S. states (with an emphasis on contested ones), and prompts the user to call contacts and discuss the upcoming vote. This most innovative feature allows users to track their call efforts, post notes in relation to each friend, and eventually compare their statistics to nationwide lead callers. In effect, this function alters a friendly discussion about politics, turning it into a quantifiable measure and, more importantly, comparable set of statistics. While its developers may not have thought of it at the time, this function was probably one of the first attempts at gamification in national politics. The second menu choice-Get Involved—gives contact details for the nearest campaign headquarters using geolocation. They both rely on the unique technological affordances of the smartphone as a mediator of sociality and space. The smoothness and immediacy of the afforded function contributes to the speed of action.

This all occurs in an atmosphere of 'post-broadcast democracy' (Prior 2007), where citizens have an increasingly selective interface with news media. Those who are interested in political information tend to be more partisan, and devote their time to searching and consuming politically oriented news material. Others have the opportunity to avoid the consumption of political news altogether, occupying themselves with entertainment content (which increasingly also includes video games). This leads to a widening gap between involved and uninvolved citizens, as knowledge is a prerequisite for public participation (Bennett and Iyengar 2008), with fatigue from the constant need to participate creating the need to find alternative means of self-expression (Schölzel 2017). To state the obvious, neither of 
the campaigns discussed in this chapter would have been possible without the ICT infrastructure available today. But such foundations include not only the oft-praised speed and horizontality, but also the embedded sociotechnical affordances of such websites as 4 Chan, Reddit and YouTube that were instrumental in the formation and subsequent distribution of various forms of memetic content. And while an attempt to understand Trump's 'Great Meme War' as only technological reeks of 'solutionism' (Morozov 2014), ignoring this component is also foolhardy.

To sum up, ICT platforms let casual politicking practitioners create interfaces for quick information provision and mobilization, which often require no—or minimal—previous knowledge or training. This opens up the opportunity for multiple actors to engage in interruptible, issue-centered political conduct.

\section{Interruptible issue-networks}

Just as game designers tend to create gradual experiences that allow players to choose their level of involvement, casual politicking is about selective levels of participation according to the individual's abilities, desires, and availability. The prime promise of this type of engagement is that of choice-for the individual, the politician, and the media. Actors in mediatized environments are constantly exposed to a multitude of topics, interpretations, focuses, analyses, framings, and counter-framings.

The marketplace of ideas has become more than just a metaphor. In a multitude of global distractions, the active citizen has an abundance of choice and can select from a wide spectrum of economic, human rights, and environmental issues, from Black Lives Matter to \#MeToo. But this also means that public interest quickly diminishes and moves onto the next hot 'issue of the day.' Consequently, many organizations focus on certain issues, rather than on an ideological bundle, 'selling' certain ideas or beliefs, while constantly framing and reframing those issues in order to take advantage of momentary alliances, public opinion shifts, a beneficial media landscape, and the like. This notion follows from the work of Richard Rogers and Noortje Marres, who developed and implemented a digital humanities tool named Issue crawler that follows web URLs based on certain keywords, tracking the amalgamation of issues between different websites (Marres and Rogers 2000; Rogers 2002, 2013; Marres 2006, 2017). What emerges from their research is a reflection of how politics works in the networked age: unsurprisingly, via networks. Rogers and Marres name them 'issue networks' after the term coined by political scientist Hugh Helco in the late 1970s. While Helco 
and others used this term to refer to the cynical practice by civil society organizations of combining forces on certain issues for purely populist goals, Marres argues that issue networks are in fact an affirmative framework, which we can use to examine activism and decision-making mechanisms.

Such networks, with their recognizable hashtags and domain names, also help concretize the debate (Burgess and Matamoros-Fernández 2016). Latour (2005a) famously criticized political scientists for being too preoccupied for too long with how to conceptualize the representational procedures in debating issues, rather than the issues (things) themselves. He argues that political contestations around topics like global warming or the war in Iraq have rendered the classic agreements on the rules and boundaries of debate null and void and that there is a need to "bring into the centre of the debate the proof of what it is to be debated" (Ibid., 8). Issue networks do just that, by allowing publics to form around a token, while still debating the exact boundaries of the issue in question (Bruns et al. 2016). Obama's app presented a quick 'cheat-sheet' of election issues, broken down by categories such as Foreign Affairs or Energy-Environment. Inside each category, a list of stances and quotes was presented, to give an idea of the candidates' approaches but also to make use of during discussions with others. By the time Trump's supporters rallied for their candidate, the issues were generated bottom-up, rather than dictated from above. An infamous example of an issue can be seen in 'Pizzagate,' where the 4 Chan community cultivated a conspiracy theory claiming that Hillary Clinton, Trump's rival for presidency, supported a hidden child-abuse ring (Bach, Jokubauskaite, and Tuters 2018). While the full details of this endeavor are beyond the scope of this chapter, suffice it to say that it ended up with an assault-rifle-wielding Trump supporter entering a pizza parlor in Washington D.C., aiming to put a stop to the abuse, an incident that was picked up and discussed in mainstream media sources. Clinton's team had to respond to those events, becoming implicated in them and shifting the discourse onto 'Pizzagate' itself, rather than the broader political issues of the campaign.

Overall, the disjointed nature of issue networks, coupled with the affordances provided by modern ICT, allow the various casual politicking practitioners to engage with selected issues and provide their followers (but subsequently, also opponents) with rapid means of interfering with the agendas of both decision-makers and the media. 


\section{Perpetual processes}

In the aftermath following Foucault's dissection of the premodern and modern societies of punishment and discipline respectively, Gilles Deleuze noted that the postmodern is the society of control (Deleuze 1992). The defining moment of the move from enforced discipline to embedded control is the perpetualness:

[I]n the disciplinary societies one was always starting again (from school to the barracks, from the barracks to the factory), while in the societies of control one is never finished with anything - the corporation, the educational system, the armed services being metastable states coexisting in one and the same modulation, like a universal system of deformation. (Ibid., 5)

Game researcher David Nieborg identifies mainstream Triple-A games as an "unfinished commodity" $(2011,36)$, arguing that by utilizing "branched serialization" (Ibid., 38), publishers turn the single game into a perpetual release cycle, generating constant additions to the original game content in the form of smaller and cheaper paid-for download packs or more contentfilled and expensive expansions.

Casual games show even stronger 'unfinished' characteristics, as the casual game revenue model resembles a service rather than a product. First, they are developed on the basis of existing and well-known genres and mechanisms (Juul 2010) to appeal to the broadest base possible. In addition, the game is often 'freemium,' meaning that it is free to play, but allows for additional (usually small) payments to unlock layers of the game previously inaccessible or to speed up the game progress (Evans 2015). The design of such games often presupposes the introduction of additional goods, and thus the game is intentionally left incomplete, with more features added as the life cycle of the game continues (Hamari 2011). Much of the freemium content consists of 'vanity items' that have no real gameplay value, and many vanity items are seasonal, such as Christmas decorations or clothing for the player's avatars or virtual domains (Fields and Cotton 2011), tied to the player's real-world time. Casual game companies often compete with one another by copying successful game elements, and because distribution is mostly online and development cycles much shorter, audiences occasionally move en masse to a more successful clone of an older game, forcing the latter's designer to embark on a new, fastpaced development and marketing campaign. Games as an industry are a 
very fitting illustration of the Deleuzian never-finishing condition that is prevalent in societies of control.

The same perpetualness exists similarly in the realm of politics, and using the epistemic prism of casual games helps us to conceptualize it. With the growth of mass self-communication and the loss of legitimacy, politicians have adopted further methods of perpetual and horizontal campaigning (Manin 1997; De Beus 2011). Instead of issuing focused messaging to the public during election time, mediatized politics constantly strives to present a vivid spectacle $^{4}$ to the ever-hungry press and the judgment of their constituents. My claim here is that understanding the ways casual games capitalize on their players' desire for short-cycle repetitive patterns of use can help us shed light on such political developments. In an increasingly informationsaturated world, games and politicians may face similar challenges: to stand out among the crowd and draw attention (Terranova 2012). Both Obama's app and Trump's campaign have done so, to varying degrees of success. To do this, both of these actants seek to rally users through 'social' methods of engagement.

\section{Sociable and collaborative}

The last defining characteristic of casual politicking is the tendency to orchestrate political action as social and collaborative. What I mean by this is that modern politics is reliant on 'social' elements as they are understood today in the popular digital discourse, as a design principle or technology powering many of our mediatized environments-from news to entertainment to education. Social elements, which are often tied to the 'Web 2.0' concept (O'Reilly 2005), include reliance on sharing and crowd-sourced elements, distributed and decentralized models, platforms rather than services, and the like. ${ }^{5}$ Social capital is a major driving force behind casual games, especially those with the free-to-play model. They use a player's computerized social connections to facilitate cooperation or completion, prompting an exchange of virtual crops or tracking a friend's progress on a leader board. Similarly, the social component of causal politicking is reliant on playful and subversive massive engagement with political content

4 Manin uses the metaphor of the theater to describe postmodern politics: politicians perform, citizens watch, journalists review.

5 For a broader discussion of the term and the associated practices, see Kylie Jarret's (2008) critical paper on Web 2.0 terminology. 
and stands in direct relation to the collapse of traditional representative parliamentary democracy and the rise of issue networks.

Communication outlets are increasingly consciously aligning themselves with certain political and/or economical actors' ideologies (Brown 2011). In this environment, framing information becomes a game of sorts. Individuals and groups are approaching the glocal (Meyrowitz 2005) and translocal (Hepp 2013) media spaces as puzzles: what is the given information, what is hidden, what is the bias of each source, how can we deconstruct, recombine, and supplement the news provided in order to make sense of the world? This approach is inherently social and ludic, and many online news communities in fact act as if they are current affairs 'fans': inquisitive, critical, fanatical, and collaborative (Gray, Sandvoss, and Harrington 2017). The gamification of various political spheres is built on such a perception of fan (and fun) engagement with the political process, for example in the practice of 'fake' social media accounts that are now widely used to parody public figures (Wilson 2011).

In the case of the Obama app, it allowed those who used it to organize themselves (independently or through Obama's local headquarters) to participate in the broadening of the network. The people using the app do this of their own volition, contributing themselves as additional nodes to Obama's network and obtaining in return the perceived benefits of connectedness. Some features, such as the leader-board caller functions, appeal directly to the users' sense of competition, whether among themselves or in the greater context of the presidential race: talk to your friends, as the winning conditions of this race can be quantifiable, and each call matters. ${ }^{6}$

Eight years later, the same principles fueled the 'Great Meme War.' The practice of 'shitposting' — creating random and deliberately annoying memes - was about playful socialization. Many of the participants in the 'war' did it, primarily, to have fun as part of a bigger community, jokingly seeing themselves as rebels and outcasts in the light of classic science fiction and fantasy tropes (Banis 2018). Just like the touch-screen game or app, innocuously taking up more and more of people's time without them realizing (Gekker 2016), the meme war grew and became serious business.

6 It is interesting to note the progress of this leaderboard approach toward the 2012 presidential elections when supporters were given the option of creating their own customizable fundraising page, which further increased the campaign personalization and potentially fostered an internal competition in terms of design, operation, and success metrics of each page. It remains to be seen whether such a distributed approach will be effective in the long run. 
Some Trump online supporters admit they regretted their actions after the election results were announced. It is conceivable to imagine them perceiving their participation through the prism of the screen, concentrated more on the immediate results — make a successful meme to antagonize the 'normies' (non-supporters) — than on the final outcome.

\section{Conclusion: Toward the ludification of politics}

At the annual Game Developers Conference in 2010, game designer Jesse Schell gave a talk in which he outlined his vision of the continued process of the ludification (and especially gamification) of society (G4TV 2010). It is not so farfetched, he argued, that the future will feature gameful elements everywhere: in our taxes, health insurance, cars, social interaction, and so on (e.g. Zimmerman 2015). He calls it the 'gamepocalypse,' a term that registers the concern he has for this state of affairs, although both he and some of his supporters noted the positive opportunities of this situation. This future is, however, uncertain, with others pointing out the backlash of people against the gameful systems, and the hyped nature of the gamification field, which may subdue the enthusiasm for implementing such design mechanisms in additional societal systems.

While gamepocalypse may be a contested vision, I wish to complicate the discussion yet further with the proposition of gamocracy as a form of political organization. It will not necessarily happen in the way Schell envisioned it, with leader boards for the best performing politicians, graphic interfaces through which parliament members could battle opposing factions, or 'political experience points' with which you could 'level up' for voting or participating in referenda (although those are some interesting experiments). It will, however, prioritize the aforementioned modes of engagement so characteristic of games and their audiences: playfulness, immediacy, and casual burst-like activity. This will result in the need for a new research framework from cultural studies and the humanities to supplement traditional tools of communication. Such a framework will focus on the citizen not only as a sender or receiver of information, but as a subject embedded in a ludic culture whose motives in the political realm may rely on the notions of fun and play no less than on ideological rational choice. 


\section{References}

Aarseth, E. J. 2001. Computer game studies, year one. Game Studies 1(1):1-15. Anderson, B. 1983. Imagined communities: Reflections on the origin and spread of nationalism. London: Verso Books.

Appadurai, A. 1996. Modernity at large: Cultural dimensions of globalization. Minneapolis, MN: University of Minnesota Press.

-. ed. 2001. Globalization. Durham, NC: Duke University Press Books.

-. 2013. The future as cultural fact: Essays on the global condition. London: Verso Books.

Bach, D., E. Jokubauskaite, and M. Tuters. 2018. The deep vernacular web. Digital Methods Initiative. http://wiki.digitalmethods.net/Dmi/ WinterSchool2018DeepVernacularWebAltRight.

Banis, D. 2018. Fictiocracy: Media and politics in the age of storytelling. Institute of Network Cultures. http://networkcultures.org/longform/2018/02/22/ fictiocracy-media-and-politics-in-the-age-of-storytelling.

Bennett, W. L, and S. Iyengar. 2008. A new era of minimal effects? The changing foundations of political communication. Journal of Communication $58(4): 707-731$.

Brants, K., and K. Voltmer. 2011a. Introduction: Mediatization and decentralization of political communication. In Political communication in postmodern democracy: Challenging the primacy of politics, eds. $\mathrm{K}$. Brants and K. Voltmer, 1-16. Houndmills: Palgrave Macmillan.

- 2011b. Political communication in postmodern democracy: Challenging the primacy of politics. Houndmills: Palgrave Macmillan.

Brown, R. 2011. Mediatization and news management in comparative institutional perspective. In Political communication in postmodern democracy: Challenging the primacy of politics, eds. K. Brants and K. Voltmer, 59-74. Houndmills: Palgrave Macmillan.

Bruns, A. 2007. Produsage. In Proceedings of the 6th ACM SIGCHI conference on creativity and cognition, Washington, DC, June 13-15, 2007, 99-106. New York: ACM.

Bruns, A., B. Moon, A. Paul, and F. Münch. 2016. Towards a typology of hashtag publics: A large-scale comparative study of user engagement across trending topics. Communication Research and Practice 2 (1): 20-46.

Burgess, J., and A. Matamoros-Fernández. 2016. Mapping sociocultural controversies across digital media platforms: One week of \#gamergate on Twitter, YouTube, and Tumblr. Communication Research and Practice 2 (1): 79-96.

Caillois, R. 1958/2001. Man, play, and games. Trans. M. Barash. Chicago, IL: University of Illinois Press. 
Cassell, J., and H. Jenkins, eds. 2000. From Barbie to Mortal Kombat: Gender and computer games. Cambridge, MA: The MIT Press.

Castells, M. 2001. The internet galaxy: Reflections on the internet, business and society. New York: Oxford University Press.

-.2007. Communication, power and counter-power in the network society. International Journal of Communication 1 (1): 238-266.

Chadwick, A. 2017. The hybrid media system: Politics and power. New York: Oxford University Press.

Christin, A. 2018. Counting clicks: Quantification and variation in Web journalism in the United States and France. American Journal of Sociology 123 (5): 1382-1415.

Cohen, B. C. 1963. The press and foreign policy. Princeton, NJ: Princeton University Press.

Coleman, S. 2006. How the other half votes: Big Brother viewers and the 2005 General Election. International Journal of Cultural Studies 9 (4): 457-479.

-. 2011. Representation and mediated politics: Representing representation in an age of irony. In Political communication in postmodern democracy: Challenging the primacy of politics, eds. K. Brants and K. Voltmer, 39-56. Houndmills: Palgrave Macmillan.

Consalvo, M. 2007. Cheating: Gaining advantage in videogames. Cambridge, MA: The MIT Press.

Corliss, J. 2011. Introduction: The social science study of video games. Games and Culture $6(1):$ 3-16.

Couldry, N., and A. Hepp. 2016. The mediated construction of reality. Malden, MA: Polity Press.

Crawford, C. 1982. The art of computer game design. http://www.vancouver. wsu.edu/fac/peabody/game-book/Coverpage.htm.

Cyan. 1993. Myst. [multiplatform]. Brøderbund. Game.

De Beus, J. 2011. Audience democracy: An emerging pattern in postmodern political communication. In Political communication in postmodern democracy: Challenging the primacy of politics, eds. K. Brants and K. Voltmer, 19-38. Houndmills: Palgrave Macmillan.

de Souza e Silva, A. 2006. From cyber to hybrid: Mobile technologies as interfaces of hybrid spaces. Space and Culture 9:261-278.

de Souza e Silva, A., and L. Hjorth. 2009. Playful urban spaces a historical approach to mobile games. Simulation \& Gaming 40 (5): 602-625.

Deacon, D., and J. Stanyer. 2014. Mediatization: Key concept or conceptual bandwagon? Media, Culture \& Society 36 (7): 1032-1044.

Deleuze, G. 1992. Postscript on the societies of control. October 59 (January): $3-7$. 
Deterding, S. 2015. The ambiguity of games: Histories and discourses of a gameful world. In The gameful world: Approaches, issues, applications, eds. S. P. Walz and S. Deterding, 23-64. Cambridge, MA: The MIT Press.

Deterding, S., D. Dixon, R. Khaled, and L. Nacke. 2011. From game design elements to gamefulness: Defining "gamification". In Proceedings of the 15th international academic MindTrek conference: Envisioning future media environments, Tampere, September 28-30, 2011, 9-15. New York: ACM.

Deterding, S, M. Sicart, L. Nacke, K. O'Hara, and D. Dixon. 2011. Gamification. Using game-design elements in non-gaming contexts. In Proceedings of the 2011 annual conference extended abstracts on human factors in computing systems, Vancouver, BC, May 7-12, 2011, 2425-2428. New York: ACM.

Entman, R. M. 1991. Framing U.S. coverage of international news: Contrasts in narratives of the KAL and Iran air incidents. Journal of Communication $41(4): 6-27$.

- 1993. Framing: Toward clarification of a fractured paradigm. Journal of Communication 43 (4): 51-58.

Evans, E. 2015. The economics of free freemium games, branding and the impatience economy. Convergence: The International Journal of Research into New Media Technologies 22 (6): 563-580.

Fields, T., and B. Cotton. 2011. Social game design: Monetization methods and mechanics. Waltham, MA: Morgan Kaufmann.

Flanagan, M. 2009. Critical play: Radical game design. Cambridge, MA: The MIT Press.

Fuchs, C. 2014. Hacktivism and contemporary politics. In Social media, politics and the state: Protests, revolutions, riots, crime and policing in the age of Facebook, Twitter and YouTube, eds. D. Trottier and C. Fuchs, 88-106. New York: Routledge.

Fuchs, M. 2012. Ludic interfaces. Driver and product of gamification. $G|A| M \mid E$ Games as Art, Media, Entertainment 1 (1). http://www.gamejournal.it/ ludic-interfaces-driver-and-product-of-gamification.

Fuchs, M., S. Fizek, P. Ruffino, and N. Schrape. 2014. Rethinking gamification. Lüneburg: meson press.

G4TV. 2010. DICE 2010: "Design out of the box" presentation. G4tv.com. http://www.g4tv.com/videos/44277/dice-2010-design-outside-the -box-presentation.

Galloway, A. 2004. Protocol: How control exists after decentralization. Cambridge, MA: The MIT Press.

Gekker, A. 2016. Casual power: Understanding user interfaces through quantification. Digital Culture \& Society 2 (1): 107-122. 
Gerlitz, C., and A. Helmond. 2013. The like economy: Social buttons and the data-intensive Web. New Media \& Society 15 (8): 1348-1365.

Gibson, J. J. 1977. The concept of affordances. In Perceiving, acting, and knowing: Toward an ecological psychology, eds. R. Shaw and J. Bransford, 62-82. Hillsdale, NJ: Lawrence Erlbaum Associates.

Goffman, E. 1974. Frame analysis: An essay on the organization of experience. London: Harper \& Row.

Graham-Harrison, E., and C. Cadwalladr. 2018. Cambridge Analytica execs boast of role in getting Donald Trump elected. The Guardian. http://www.theguardian.com/uk-news/2018/mar/2o/ cambridge-analytica-execs-boast-of-role-in-getting-trump-elected.

Gray, J., C. Sandvoss, and C. L. Harrington, eds. 2017. Fandom: Identities and communities in a mediated world. New York: New York University Press.

Hamari, J. 2011. Perspectives from behavioral economics to analyzing game design patterns: Loss aversion in social games. Paper presented at The 2011 annual conference on human factors in computing systems, Vancouver, BC, Canada, May 7-12, 2011.

Helmond, A. 2015. The platformization of the Web: Making Web data platform ready. Social Media + Society 1 (2). http://doi.org/10.1177/2056305115603080.

Hepp, A. 2012. Mediatization and the 'moulding force' of the media. Communications 37 (1):1-28.

-. 2013. Cultures of mediatization. Malden, MA: Polity Press.

Hepp, A., S. Hjarvard, and K. Lundby. 2015. Mediatization: theorizing the interplay between media, culture and society. In Media, Culture \& Society $37(2): 314-324$.

Hjarvard, S. 2008. The mediatization of society. A theory of the media as agents of social and cultural change. Nordicom Review: Nordic Research on Media \& Communication 29 (2): 105-134.

- 2013. The mediatization of culture and society. London: Routledge.

Huizinga, J. 1970. Homo ludens: A study of the play-element in culture. London: Temple Smith.

Iyengar, S. 1994. Is anyone responsible? How television frames political issues. Chicago, IL: University of Chicago Press.

Jahn-Sudmann, A., and R. Stockmann. 2008. Computer games as a sociocultural phenomenon: Games without frontiers, war without tears. Houndmills: Palgrave Macmillan.

Jarrett, K. 2008. Interactivity is evil! A critical investigation of Web 2.0. First Monday 13 (3): 34-41.

Jenkins, H. 2006a. Fans, bloggers, and gamers: Media consumers in a digital age. New York: New York University Press. 
—. 2006b. Convergence culture: Where old and new media collide. New York: New York University Press.

-. 2012. Textual poachers: Television fans and participatory culture. New York: Routledge.

Juul, J. 2003. The game, the player, the world. In Proceedings of Level Up: Digital games research conference, Utrecht, November 4-6, 2003, eds. M. Copier and J. Raessens, 30-45. Utrecht: Utrecht University.

-. 2010. A casual revolution: Reinventing video games and their players. Cambridge, MA: The MIT Press.

King. 2012. Candy Crush Saga. [multiplatform]. King. Game.

Kiyohara, S. 2009. A study on how technological innovation affected the 2008 U.S. Presidential Election: Young voters' participation and Obama's victory. In Proceedings of the gth annual international symposium on applications and the internet, Bellevue, WA, 20-24 July 2009, 223-226. Washington, DC: IEEE.

Krotz, F. 2007. The meta-process of 'mediatization' as a conceptual frame. Global Media and Communication 3 (3): 256-26o.

Lakoff, G., and M. Johnson. 1980. Metaphors we live by. Chicago, IL: University of Chicago Press.

- 1999. Philosophy in the flesh: The embodied mind and its challenge to Western thought. New York: Basic Books.

Latour, B. 1987. Science in action. Cambridge, MA: Harvard University Press.

-.2005a. From Realpolitik to Dingpolitik or how to make things public. In Making things public: Atmospheres of democracy, eds. P. Weibel and B. Latour, 14-44. Cambridge, MA: The MIT Press.

- 2005b. Reassembling the social:An introduction to Actor-Network-Theory. Oxford: Oxford University Press.

Law, J. 1992. Notes on the theory of the Actor-Network: Ordering, strategy, and heterogeneity. Systems Practice 5 (4): 379-393.

Lovink, G., and M. Tuters. 2018. They say we can't meme: Politics of idea compression. Copyriot.com. http://non.copyriot.com/ they-say-we-cant-meme-politics-of-idea-compression.

Lundby, K. 2009. Mediatization: Concept, changes, consequences. New York: Peter Lang.

Manin, B. 1997. The principles of representative government. New York: Cambridge University Press.

Marres, N. 2006. Net-work is format work: Issue networks and the sites of civil society politics. In Reformatting politics: Information technology and global civil society, eds. J. Anderson, J. Dean, and G. Lovink, 3-17. New York: Routledge. 
—. 2017. Digital sociology: The reinvention of social research. Malden, MA: Polity Press.

Marres, N., and R. Rogers. 2000. Depluralising the Web and repluralising public debate: The case of the GM food debate on the web. In Prefered placement: Knowledge politics on the Web, 113-135. http://dare.uva.nl/record/85893.

McCombs, M. E., and D. L. Shaw. 1972. The agenda setting function of mass media. Public Opinion Quarterly 36 (2): 176-187.

McGonigal, J. 2011. Reality is broken: Why games make us better and how they can change the world. New York: Penguin Press.

Meyrowitz, J. 2005. The rise of glocality. In A sense of place: The global and the local in mobile communication, ed. J. K. Nyíri, 21-30. Vienna: Passagen Verlag.

Mitchell, W. J. 2003. Me++: The cyborg self and the networked city. Cambridge, MA: The MIT Press.

Moore, C. 2011. The magic circle and the mobility of play. Convergence: The InternationalJournal of Research into New Media Technologies 17 (4): 373-387.

Morozov, E. 2014. To save everything, click here: The folly of technological solutionism. New York: PublicAffairs.

Nagle, A. 2017. Kill all normies: Online culture wars from 4chan and tumblr to Trump and the Alt-Right. Winchester, UK: Zero Books.

Nagy, P., and G. Neff. 2015. Imagined affordance: Reconstructing a keyword for communication theory. Social Media + Society 1 (2).

Neiwert, D. 2017. Alt-America: The rise of the radical right in the age of Trump. London: Verso Books.

Nieborg, D. B. 2011. Triple-A: The political economy of the blockbuster video game. PhD thesis. Amsterdam: University of Amsterdam.

Nielsen, J., and K. Pernice. 2008. Eyetracking web usability. Berkeley, CA: New Riders Publishers.

Norman, D. A. 1988. The psychology of everyday things. New York: Basic Books.

-. 2002. The design of everyday things. New York: Basic Books.

Nunes, M. 2006. Cyberspaces of everyday life. Minneapolis, MN: University of Minnesota Press.

Ohlheiser, A. 2016. 'We actually elected a meme as president': How 4chan celebrated Trump's victory. The Washington Post. http://www.washingtonpost.com/news/the-intersect/wp/2016/11/og/we-actually-elected-ameme-as-president-how-4chan-celebrated-trumps-victory.

O'Reilly, T. 2005. What is Web 2.0: Design patterns and business models for the next generation of software. http://www.oreillynet.com/pub/a/ oreilly/tim/news/2005/o9/30/what-is-web-2o.html.

Pargman, D., and P. Jakobsson. 2008. Do you believe in magic? Computer games in everyday life. European Journal of Cultural Studies 11 (2): 225-244. 
Pearce, C. 2008. The truth about baby boomer gamers. Games and Culture 3 (2): 142-174.

Philips, T. 2016. Discussions with developers: F2P and the changing landscape of games. In Social, casual, mobile: Changing games, eds. M. Willson and T. Leaver, 61-74. New York: Bloomsbury Academic.

Pick, C. Y. 2010. Mobile strategies in political communication. Washington: American University.

Poster, M. 2004. Digitally local communications: Technologies and space. Paper presented at The global and the local in mobile communication: Places, images, people, connections, Budapest, June 10-12, 2004.

Prior, M. 2007. Post-broadcast democracy: How media choice increases inequality in political involvement and polarizes elections. New York: Cambridge University Press.

Raessens, J. 2006. Playful identities, or the ludification of culture. Games and Culture $1(1)$ : 52-57.

-. 2014. The ludification of culture. In Rethinking gamification, eds. M. Fuchs, S. Fizek, P. Ruffino, and N. Schrape, 91-114. Lüneburg: meson press.

- 2016. Game studies. In The international encyclopedia of communication theory and philosophy, eds. K. B. Jensen, R. T. Craig, J. D. Pooley, and E. W. Rothenbuhler, 1-5. Hoboken, NJ: Wiley.

Ritchey, R. 2008. Obama 'o8 iPhone Application Review. Youtube. http:// www.youtube.com/watch?v=8X-FX 58 lfGs.

Rogers, R. 2002. Operating issue networks on the Web. Science as Culture 11 (2): 191-213.

—. 2013. Digital methods. Cambridge, MA: The MIT Press.

Roig, A., G. San Cornelio, E. Ardèvol, P. Alsina, and R. Pagès. 2009. Videogame as media practice. Convergence: The International Journal of Research into New Media Technologies 15 (1): 89-103.

Rovio Entertainment. 2009. Angry Birds. [Android/iOS/Windows Phone]. Chillingo. Game.

Sagolla, D. 2008. iOSDevCamp - Obama '08 iPhone App. iOsDevCamp. http:// www.iosdevcamp.org/2008/10/02/obama-08-iphone-app.

Salen, K., and E. Zimmerman. 2004. Rules of play: Game design fundamentals. Cambridge, MA: The MIT Press.

Schäfer, M. T. 2011. Bastard culture! How user participation transforms cultural production. Amsterdam: Amsterdam University Press.

Scheufele, D. A., and D. Tewksbury. 2007. Framing, agenda setting, and priming: The evolution of three media effects models. Journal of Communication 57 (1): 9-20. 
Schölzel, H. 2017. Backing away from circles of control: A re-reading of interpassivity theory's perspectives on the current political culture of participation. Empedocles: European Journal for the Philosophy of Communication 8 (2): 187-203.

Shaw, A. 2010. What is video game culture? Cultural studies and game studies. Games and Culture 5 (4): 403-424.

Shifman, L. 2014. Memes in digital culture. Cambridge MA: The MIT Press. Sicart, M. 2014. Play matters. Cambridge, MA: The MIT Press.

Simon, B., K. Boudreau, and M. Silverman. 2009. Two players: Biography and 'played sociality' in Everquest. Game Studies 9 (1). http://gamestudies. org/ogo1/articles/simon_boudreau_silverman.

Sony Online Entertainment. 1999. Everquest. [Windows/MacOS]. Sony Online Entertainment. Game.

Steinkuehler, C. A. 2004. Learning in massively multiplayer online games. In Proceedings of the 6th international conference on learning sciences, eds. Y. B. Kafai, W. A. Sandoval, N. Enyedy, A. S. Nixon, and F. Herrera, 521-528. Mahwah: Erlbaum.

Sutton-Smith, B. 2005. Play and ambiguity. In The Game design reader: A rules of play anthology, eds. K. Salen and E. Zimmerman, 296-313. Cambridge, MA: The MIT Press.

Terranova, T. 2012. Attention, economy and the brain. Culture Machine 13 (1).

Tufekci, Z. 2017. Twitter and tear gas: The power and fragility of networked protest. New Haven, CT: Yale University Press.

Van Dijk, J. 2005. The network society: Social aspects of new media. London: Sage Publications.

Walz, S. P., and S. Deterding, eds. 2015. The gameful world: Approaches, issues, applications. Cambridge, MA: The MIT Press.

Whitlatch, A. 2015. A day with Edward Tufte.Medium. http://medium.com/@ ashley_mw/a-day-with-edward-tufte-7b142cec76of.

Wilson, J. 2011. Playing with politics: Political fans and Twitter faking in post-broadcast democracy. Convergence: The International Journal of Research into New Media Technologies 17 (4): 445-461.

Woolgar, S. 1990. Configuring the user: The case of usability trials. The Sociological Review 38:58-99.

Zimmerman, E. 2015. Manifesto for a ludic century. In The gameful world: Approaches, issues, applications, eds. S. P. Walz and S. Deterding, 19-22. Cambridge, MA: The MIT Press. 


\section{About the author}

Alex Gekker is a Lecturer in the departments of Media and Culture at the University of Amsterdam and Media \& Communication at Erasmus University Rotterdam. He completed his PhD at Utrecht University in 2016, working on the relations between mapping, digital interfaces, and power. He is interested in ways socio-technical systems are designed to influence users, and his research has touched upon the quantification and datafication of society, the experience economy, and interface critique. Additionally, he has participated in the field of games and play studies throughout his career, both as a scholar and practitioner. He has launched an early prototype of a location-based game, was part of the co-founding team of the Games for Health Europe series of conferences, and now co-designs Playfields, a playful tool for teaching fieldwork. 